rev.relac.int.estrateg.segur.7(2):221-244,2012

\title{
LA NARCOTIZACIÓN DE LAS RELACIONES COLOMBIA-ESTADOS UNIDOS*
}

\author{
Merly Guanumen Pacheco*
}

"Si no podemos destruir la amenaza de las drogas en América, entonces seguramente el tiempo nos destruirá.

Yo no estoy preparado para aceptar esta alternativa". Richard Nixon, 1968

"La coca, que solía masticar una minoría indígena en nuestras montañas aisladas, se convirtió en un artículo de lujo gracias a la política del gobierno norteamericano. Poco tuvimos que ver con ella, ni en sus orígenes, ni en sus resultados. Pero ahora somos 'The Colombian Connection'". Alberto Lleras Camargo, 1979

* Este artículo hace parte del proceso de investigación doctoral "Actores no estatales en política internacional: El caso del activismo transnacional de derechos humanos sobre Colombia". Estas reflexiones fueron parte del seminario Historia de las Relaciones Colombia-Estados Unidos, visto en el marco del proceso de formación del doctorado en Estudios Políticos y Relaciones Internacionales de la Universidad Nacional de Colombia.

** Administradora Pública de la Escuela Superior de Administración Pública de Bogotá; magister en Análisis de Problemas Políticos, Económicos, Internacionales contemporáneos de la Universidad Externado de Colombia, el Instituto de Estudios Políticos de París y el Instituto de Altos Estudios para el Desarrollo; Estudiante del Doctorado en Estudios Políticos y Relaciones Internacionales de la Universidad Nacional de Colombia, línea Estudios Internacionales. Gestora Pública en las áreas de educación superior, cultura, ciencia y tecnología.

Correo electrónico: merlyguanumen@gmail.com 


\title{
RESUMEN
}

En este artículo se presentan los acontecimientos que incorporaron de manera prioritaria la guerra contra las drogas en la agenda de las relaciones Colombia-Estados Unidos, a partir de la coincidencia en las posturas oficiales respecto al uso de sustancias psicoactivas. Se analiza la manera en que las drogas devienen un tema central en la política de Estados Unidos y a nivel mundial, luego de los cambios de la década del sesenta y la guerra de Vietnam y cómo el tráfico ilegal se afianzó en Colombia, implementándose desde temprano, como respuesta, una estrategia gubernamental represiva. La coincidencia de argumentos ideológicos y la dimensión del problema impidieron que Colombia elaborara una postura propia, asumiendo las políticas de interdicción de los Estados Unidos.

Palabras clave: Guerra contra las drogas, narcotráfico, prohibicionismo, narcotización, relaciones Estados Unidos-Colombia.

\section{DRUG MANAGEMENT IN THE RELATIONS COLOMBIA - UNITED STATES}

\begin{abstract}
In this article, a presentation is made of the events that in a priority way, included the war against the drugs in the agenda of the relations Colombia-United States, as there was a coincidence in the official positions regarding the use of psychoactive substances. An analysis is made of the way drugs became a central issue in U. S. politics and on a worldwide basis, after the changes of the sixties and the Vietnam War and how the illegal traffic took hold in Colombia very early on and, in response, a repressive governmental strategy was implemented. The coincidence of ideological arguments and the dimension of the problem prevented Colombia from devising its own stand on this issue, instead taking on the interdiction policies of the United States.
\end{abstract}

Key Words: War on drugs, drug trafficking, prohibition, drug management, United States Colombia relations.

\section{A NARCOTIZAÇÃO DAS RELAÇÕES COLÔMBIA- ESTADOS UNIDOS}

\section{RESUMO}

Apresentam-se a um novo público os acontecimentos que levaram à incorporação prioritária da guerra contra as drogas na agenda das relações EUA-Colômbia, a partir da coincidência nas posições oficiais sobre o uso de substâncias psicoativas. Analisa-se a maneira como as drogas se tornam uma questão central na política dos EUA e no âmbito mundial após as mudanças dos 
anos sessenta e a Guerra do Vietnã e como o tráfico se afiançou na Colômbia, implementandose desde cedo, como resposta, uma estratégia governamental repressiva. A coincidência de argumentos ideológicos e a dimensão do problema impediram que a Colômbia elaborasse uma postura própria, assumindo as políticas de interdição dos EUA.

Palavras-chave: Guerra contra as drogas, narcotráfico, proibição, narcotização, relações EUAColômbia.

\section{INTRODUCCIÓN}

Los colombianos nacidos después de la segunda mitad de los años setenta asumen como un hecho dado la centralidad del tema del narcotráfico y la guerra contra las drogas en las relaciones entre Colombia y Estados Unidos. Sin embargo, hace apenas cuarenta años estas problemáticas no estaban presentes en la agenda entre los dos países y no permeaban todos los ámbitos de interacción binacional, como sí sucede hoy.

La literatura académica sobre el narcotráfico y su incidencia en los aspectos sociales, políticos, económicos, ambientales y culturales, así como sus efectos en las relaciones internacionales de Colombia, es amplia y continua. El interés de este artículo, más que aportar nuevos datos, enfoques o teorías a los ya existentes, es volver a narrar algunos hechos fundamentales a una nueva generación de lectores que, por motivos académicos o simple interés personal, quieren comprender el origen de estos fenómenos y la manera como empezaron a "narcotizarse" las relaciones internacionales entre ambos países.

Esta tarea resulta más pertinente ahora que México se encuentra en el centro de la guerra contra las drogas y que diversas voces del continente, especialmente Colombia y algunos países de Centroamérica, comienzan a plantear la necesidad de evaluar la estrategia y formular otras alternativas ante el evidente fracaso, dada la persistencia del problema, más allá de las medidas de fuerza ya experimentadas. Así lo señaló en entrevista para el diario El Tiempo de Bogotá el presidente de Colombia, Juan Manuel Santos: "Hemos perdido nuestros mejores hombres, derramado la mayor cantidad de sangre y pagado el costo más alto. Y a los 40 años uno tiene que parar y reflexionar. ¿Estamos avanzando? En el caso colombiano hemos sido relativamente exitosos, pero el narcotráfico sigue y nuestro relativo éxito tiene en serios problemas al resto de la región" (El Tiempo.com, 2012). Revisar la implementación del paradigma prohibicionista de Estados Unidos en Colombia, aprendiendo de sus aciertos y errores, puede aportar elementos de juicio para replantear el tratamiento global del problema de las drogas y sobre todo para no cometer los mismos errores en naciones que hoy se enfrentan a este desafío.

Este artículo se encuentra estructurado de la siguiente manera: en primer lugar, se hará un breve recorrido de los antecedentes del prohibicionismo, base moral legitimadora de la guerra contra 
las drogas en Estados Unidos (EE.UU.) y también en Colombia, y se mostrará cómo las percepciones culturales sobre el problema han coincidido en ambas sociedades, condicionando en el largo plazo las repuestas institucionales al fenómeno una vez este devino en un tema de seguridad nacional.

Luego se expondrán los factores sociales, políticos, económicos y culturales previos que incitaron el tema dentro de la agenda política de los dos países en un momento muy concreto de la historia: el período de 1978 a 1982, correspondiente a los gobiernos de Julio César Turbay Ayala (1978-1982) en Colombia, y de Jimmy Carter (1977-1981) y Ronald Reagan (1981-1989) en los Estados Unidos.

Se concluirá, siguiendo la tesis de Juan Gabriel Tokatlian (1991), que ante el aumento creciente de la demanda de drogas ilícitas en los Estados Unidos y el igualmente creciente impacto del narcotráfico en todos los niveles de la sociedad, el Estado colombiano no desarrolló una estrategia consciente y efectiva para el manejo del problema, lo cual posibilitó que el diagnóstico estadounidense terminara siendo el único "internalizado" en la agenda binacional, resultando en la priorización de la guerra contra las drogas a partir de coordenadas establecidas en Washington y no en Bogotá. De esta forma el tema quedó anclado a las prioridades de seguridad de Estados Unidos, responsabilizándose políticamente al Estado colombiano, como país productor, del incremento del tráfico y consumo en ese país, en razón a las percepciones moralizantes del problema de las drogas, que asume que esta situación se debe sobre todo a factores externos "dañinos", ajenos a la sociedad estadounidense. Por ello, como lo veremos más adelante, la respuesta institucional será la guerra contra las drogas y el incremento de la criminalización y penalización a los consumidores.

Tal vez volver los ojos al problema de la adicción en los países industrializados, y cada vez más en los menos desarrollados, puede dar salidas a un esquema punitivo que para Colombia ha representado un altísimo costo, sobre todo en vidas humanas y en afectación de ecosistemas. Se trata de construir una estrategia integral que considere simultáneamente los dos lados del problema, la producción y el consumo, y que se desarrolle bajo un esquema de corresponsabilidad global entre países productores, comercializadores, consumidores, proveedores de insumos, armas y de paraísos fiscales para el blanqueo de los dineros ilícitos del negocio. El mayor peso no puede seguir recayendo en los países productores, como Colombia o México¹.

1. Si bien Colombia sigue siendo el principal productor de la cocaína que se consume en los Estados Unidos, hoy son los narcotraficantes mexicanos los que controlan buena parte de su distribución, así como de la heroína, marihuana y metanfetamina que sale desde México hacia Estados Unidos y el resto del mundo. "Además, los informes de la Evaluación Nacional de la Amenaza de la Droga de EE.UU para 2009 afirman que los cárteles mexicanos controlan la distribución de las drogas en la mayoría de las ciudades de EE.UU., a través de redes en al menos 230 ciudades estadounidenses" (Bussey, 2009, p. 25). 


\section{PROHIBICIONISMO Y CONTROL, ENFOQUES COMPARTIDOS FRENTE AL PROBLE- MA DEL CONSUMO DE DROGAS.}

La prohibición del uso personal de sustancias psicoactivas ${ }^{2}$ es la racionalidad de base en la estrategia de control de drogas de los Estados Unidos. Dicho enfoque supone que la ingesta de sustancias de efecto estimulante, deprimente, narcótico o alucinógeno es perjudicial para el individuo y la sociedad, y que por lo tanto es deber de las instituciones tomar medidas para que tales sustancias no lleguen a manos de los ciudadanos. Esto se logra de dos maneras: penalizando vigorosamente a usuarios, productores y distribuidores, y reduciendo la oferta en los países de origen para que se incrementen con ello los precios del mercado y se disminuya el universo de consumidores (Matthiesen, 2000).

El debate por el control de drogas se empezó a dar en el siglo XIX en los Estados Unidos con muchas de las características que asume hoy todavía, y el prohibicionismo se institucionalizará mediante la Ley Harrison de 1914. Esta ley prohibía el consumo de opio, morfina, heroína y cocaína sin receta médica, y buscaba detener la aparición de nuevos sujetos adictos. Para el reconocido historiador español de las drogas Antonio Escohotado (1996), el proceso de prohibición de estas sustancias fue el resultado de dos fenómenos del siglo XIX: las migraciones masivas de europeos hacia Estados Unidos (y en menor medida de asiáticos y mexicanos), y el crecimiento del sector médico y farmacéutico de ese país.

La migración desencadenó en los sectores más religiosos y puritanos una reacción contra "las masas de nuevos inmigrantes y las grandes urbes", asociando el origen étnico, religioso o social con el uso de uno u otro estimulante, asignándosele a los nuevos ciudadanos, en consecuencia, una condición de inferioridad moral y económica. Por otra parte, el crecimiento y modernización del Estado provocó la constitución de un sector profesional médico y farmacéutico que a la larga desplazaría a las asociaciones religiosas en las labores sanitarias, dándose así "una feroz batalla de médicos y farmacéuticos contra curanderos y herboristas, cuyo principal objeto es consolidar un monopolio de los primeros sobre las drogas". En 1900, la mayoría de sustancias que luego serán prohibidas (opio, morfina, heroína, cocaína), se encuentran disponibles en droguerías y farmacias, sin prescripción médica y se comercializan sin ninguna restricción (Escohotado, 1996, p. 98).

En los debates públicos para la prohibición del consumo de alcohol (Ley Volstead de 1919), encabezados por la Anti Saloon-League, con el apoyo de la Asociación Médica Americana, y la Asociación Farmacéutica, también se combinarán estos discursos e intereses, frente a

2. Se entenderá de manera sinónima drogas o sustancias psicoactivas como aquella "sustancia química, legal o ilegal, natural o sintética, que actúa sobre el sistema nervioso central y que altera la percepción, los estados emocionales, la consciencia y la conducta" (Larreamendy-Joerns \& Vence, 2011). 
una nueva oportunidad para extender la prohibición a todas las drogas. A la larga, estas dos últimas asociaciones también sufrirán las consecuencias de un prohibicionismo extremo que en los años veinte y treinta terminará penalizando a más de 40.000 profesionales, en razón a estrategias de incriminación desarrolladas por policías disfrazados de adictos que acusan al personal sanitario por "conspiración para violar la ley Harrison" (Escohotado, 1996, p. 105).

Por vía del expansionismo territorial y comercial de Estados Unidos de finales del siglo XIX y comienzos del XX, el panorama moral prohibicionista que determina el debate interno en torno al control de las drogas se proyecta a nivel internacional, y como una zanahoria ofrecida por el tío Sam, después del garrote comercial a la China, Teodoro Roosevelt decide apoyar las intenciones de sus propios diplomáticos para buscar la prohibición del uso no médico del opio a nivel mundial, convocando la conferencia de Shangai (1906) a la que acudirán tan solo 12 países $^{3}$. Si bien Estados Unidos no encontró el apoyo que esperaba, da el primer paso hacia el posicionamiento moral y prohibicionista del tema de las drogas a nivel global. Este empezará a hacerse realidad tras el incremento de la hegemonía económica estadounidense y la firma de la Convención de La Haya o Convención Internacional del Opio de 1912, suscrita inicialmente por 13 naciones y luego extendida a otras jurisdicciones con la incorporación posterior en el Tratado de Versalles de 1919, al finalizar la Primera Guerra Mundial. La Gran Guerra derivará en la constitución de la Sociedad de las Naciones, institución que será la encargada de velar por el cumplimiento de la Convención, y, más adelante, al concluir la Segunda Guerra Mundial, este papel será asumido por las Naciones Unidas (1945), que con nuevas normas ampliará la prohibición a otras drogas como la marihuana o la cocaína. Con la Convención Única sobre Estupefacientes de Naciones Unidas (1961), que "enumera todas las sustancias sometidas a fiscalización y crea la Junta Internacional de Fiscalización de Estupefacientes", se instala definitivamente el prohibicionismo en la legislación internacional (Naciones Unidas. Oficina contra la Droga y el Delito, 2008).

La interpretación de las drogas ilícitas como "malas" y "peligrosas" se ha desarrollado en los Estados Unidos bajo la idea de que las drogas constituyen un mal moral para la sociedad, y que además son una amenaza para la seguridad nacional (Tickner \& Cepeda, 2011). El primer supuesto se explica por los valores morales dominantes en dicha sociedad, basados sobre todo en la ética protestante de la mayoría blanca, conservadora y anglosajona, orientadores de los debates políticos internos e internacionales. Así lo observan los investigadores británicos Micklethwait y Wooldridge, en su libro "Una Nación Conservadora" (2006, p. 23):

3. Desde el siglo XVIII el consumo de opio se constituyó en un grave problema para China, agravado posteriormente por la incursión de las potencias occidentales y especialmente de Gran Bretaña que sometió a este país a un comercio obligado de este producto, desencadenándose lo que se conoce como las guerras del opio, la primera entre 1839 y 1842, y la segunda entre 1857 y 1860. 
Estados Unidos defiende el derecho a llevar armas, la pena de muerte y severas leyes penales (...), está mucho más predispuesto que sus aliados a considerar el uso de la fuerza, incluso unilateralmente, en conflictos humanos y desconfía de los tratados mucho más que aquellos. Los ciudadanos estadounidenses son mucho más religiosos que los ciudadanos europeos y conservan valores morales mucho más tradicionales. Estados Unidos es uno de los pocos países ricos donde el aborto es un tema político que galvaniza la opinión pública, y quizá sea el único donde la mitad de las familias suelen rezar antes de las comidas (...).

Un patrón común en los Estados Unidos cuando se incrementa el consumo de estas sustancias, es percibir el problema como un asunto "externo, extranjero, antisocial" y relacionado "negativamente con minorías étnicas, anarquistas o con elementos al margen de la sociedad estadounidense" (Matthiesen, 2000, p. 39). Este marco explicativo de la realidad permitió la expedición de normas para controlar no sólo el uso de las sustancias psicoactivas sino también a las poblaciones asociadas a su consumo: asiáticos frente al opio, mexicanos en el caso de la marihuana y negros pobres para la cocaína; se percibía a dichas poblaciones, y las sustancias mismas, como factores de "riesgo", de "depravación" y de comportamientos "desviados" del cuerpo social.

\subsection{EL PROHIBICIONISMO EN COLOMBIA}

En Colombia el prohibicionismo también ha asumido un sesgo racial hacia el control de poblaciones minoritarias o "desviadas". Así el control de la planta y del consumo de hoja de $\mathrm{coca}^{4}$, siendo una práctica ancestral de las comunidades indígenas de Suramérica y que por distintos motivos (hábitos, características del producto, forma de consumo) no encontró eco en los demás sectores de la población blanca y mestiza, ha servido para incitar el control social de estas poblaciones.

En un principio la Iglesia Católica, a través del Tribunal del Santo Oficio de Cartagena de Indias (1610-1825), intentó impedir el uso de la hoja en "idolatrías, ceremonias y hechicerías"; luego diversas medidas de higiene pública que mostraban "un desprecio generalizado hacia la población indígena y sus costumbres" (López, 2000, p. 86), como la prohibición de la chicha en 1948, o incluso análisis académicos prejuiciados sobre las consecuencias del consumo de coca elaborados por la Facultad de Medicina de la Universidad Nacional ${ }^{5}$ mostraron

4. Es necesario distinguir entre el uso tradicional y ritual de la hoja de coca de las poblaciones indígenas andinas, del uso recreativo reciente de su principal derivado, el alcaloide conocido como cocaína.

5. López cita el siguiente texto: "Si tenemos presente que desde la edad de siete u ocho años comienza el niño a mascar coca, nos explicamos fácilmente el desarrollo retardado y mediocre del indígena (...) Por lo común, los hijos de los viejos mascadores son idiotas y degenerados. Son una pesada carga para el Estado. Fácilmente sugestionables, se les induce sin dificultad a la comisión de crímenes espantosos. Su moral es la fuerza del instinto. Si no tiene coca, ni dinero para conseguirla hurtan, roban, hacen cosas increíbles para conseguirla...Y por sobre todas las cosas [el indígena] es mentiroso. Torpemente, estúpidamente mentiroso. La idiotez es su patrimonio común" (López, 2000, p. 86). 
un sesgo en la formulación de políticas de control de poblaciones asimilables a las acciones norteamericanas.

Dicha actitud de desprecio hacia los indígenas era generalizada entre las élites y las clases medias, especialmente en las zonas de mayor presencia indígena como el Cauca, en donde el prejuicio "sanitario" hacia la coca era mayor a pesar de la importancia de esta planta en la economía local: los dueños de haciendas y plantaciones la usaban como medio de pago de las poblaciones nativas vinculadas a la producción agrícola, e incluso por fuera de este contexto la hoja de coca conservaba un valor de venta intrínseco. No obstante, la persecución fue tan efectiva que para 1947 el gobierno nacional expidió un decreto prohibiendo el pago de salarios o cualquier clase de remuneraciones laborales con "bebidas alcohólicas o en hoja de coca" (López, 2000). Además ilegalizó, junto con la marihuana, su cultivo y comercio, ordenando la destrucción de plantaciones existentes y el decomiso de las hojas, a menos que estas estuvieran a la venta en farmacias autorizadas. Estas decisiones nunca fueron consultadas con las comunidades indígenas. Las presiones ejercidas por los hacendados del Cauca afectados con la medida lograron aplazar la aplicación del decreto por un año más, coincidiendo con los hechos del 9 de abril de 1948, lo que dejó la orden sin piso político ni respaldo institucional para hacerla cumplir.

La prohibición no se centró sólo en la hoja de coca. El uso del opio y sus derivados, así como de la marihuana, también fueron objeto de regulación y sanción legal desde muy temprano, a través de la Ley 11 del 15 de septiembre de $1920^{6}$. En estas primeras décadas las regulaciones tenían un espíritu más "sanitario" que punitivo, buscando reducir el potencial de consumidores y adictos bajo un enfoque que hoy se denominaría de "salud pública" para el control de conductas desviadas.

La Ley 118 de 1928 impuso la pena de prisión para los comerciantes ilegales de las "drogas heroicas" y ordenó tratamientos obligatorios para los consumidores; avanzando la primera mitad del siglo se prohibió expresamente el cultivo o consumo de marihuana, incluso imponiendo penas como "relegación a colonia agrícola de dos a cinco años" o la imposición de "casa de reposo u hospital" para los adictos, en 1964. El uso de la Cannabis Indica fue incluso asociado con el homosexualismo, condenados ambos de la misma manera: "el consumo de marihuana puede fácilmente transformar a una persona sexualmente normal en un homosexual..., un despreciable homosexual" (López, 2000, p. 94, cita al profesor de farmacología de la

6. El Artículo 1 de esta ley señalaba: “No podrán venderse las siguientes sustancias por mayor ni al detal, ni en recetas o prescripciones, sino por orden o receta escrita de un médico o licenciado en medicina, dentista o veterinario graduados en Facultades aceptadas por el Gobierno: cocaína o sus sales, cocaína, alfa o beta, sean solas o combinadas con otras sustancias, y sea cual fuere el nombre con que se las distinga; opio o preparaciones oficinales de éste, como láudano, opio concentrado, bálsamo anodino, etc., codeína y morfina o las sales de éstas o sus derivados; heroína, belladona, atropina o sus sales; cánnabis índica y las demás sustancias de esta misma clase" (Congreso de Colombia, 1920). 
Universidad de Antioquia, Guillermo Cano Puerta, quien escribía estas frases en 1967 en su reconocido libro "Marihuana "yerba maldita"").

Si bien Colombia no escapaba a las crecientes corrientes prohibicionistas impulsadas por los Estados Unidos en su territorio y hacia la legislación internacional, la prohibición de la hoja en el país se adoptó de forma autónoma, en función de sus propios prejuicios racistas y sanitarios frente a la coca y a la población consumidora, más que por su condición de materia prima para la cocaína. Incluso en 1939 Colombia le solicita a la Sociedad de Naciones el establecimiento de limitaciones a su producción, posición que puede deberse a la poca importancia de este producto en la economía nacional, en contraste con los casos de Perú y Bolivia (López, 2000). Esta realidad podría ayudar a explicar también la posterior aceptación en Colombia de la erradicación de cultivos de coca como una estrategia legitima para el control del tráfico ilícito de cocaína.

La coca no será objeto de prohibición en la función específica de la producción de la cocaína hasta 1961 con la proclamación de la Convención Única sobre estupefacientes por la Organización de las Naciones Unidas, que incluye a la cocaína en la lista de "estupefacientes" sujetos a "medidas de fiscalización" (Organización de las Naciones Unidas, 1961), e incluso el cultivo de la planta no será un tema importante de las relaciones entre Colombia y EE.UU. hasta los años ochenta.

De esta manera, la moral prohibicionista imperante en ambos países frente al consumo de sustancias psicoactivas, ayudará a explicar más adelante, en desarrollo de los acontecimientos, la aceptación por parte de Colombia de la estrategia de guerra contra las drogas como un camino para proteger a la sociedad y sus valores de la "amenaza" de las drogas.

\section{LA GUERRA CONTRA LAS DROGAS, LA RESPUESTA ESTADOUNIDENSE AL AUMEN- TO DEL CONSUMO Y LA PRODUCCIÓN.}

El tráfico ilegal de drogas es en esencia un asunto internacional, dado que los procesos de producción, procesamiento, comercialización, consumo y circulación de los capitales derivados del negocio involucran a muchos países. Por esta razón, y también por la aceptación de la percepción estadounidense del problema, los organismos multilaterales como Naciones Unidas, o la Organización de Estados Americanos, consideran al narcotráfico como un asunto de seguridad global, que amenaza a la soberanía y a la capacidad de los Estados, por cuenta del poder corruptor y desestabilizador de las mafias transnacionales?

7. Por ejemplo, Antonio María Costa, Director Ejecutivo la Oficina de las Naciones Unidas contra la Droga y el Delito (UNODC), en un informe publicado en el 2010 señaló que "La delincuencia organizada se ha globalizado convirtiéndose en una de las primeras potencias económicas y armadas del mundo" (ONUDD, 2010). 
El aumento progresivo del consumo en los Estados Unidos otorgó a Colombia el rol de proveedor en medio de una demanda creciente, con lo cual se consolidaron empresas ilegales para la producción, transporte y comercialización de la droga, obligando al Estado colombiano a responder a la presión bilateral y multilateral para detener el poder de las mafias. Las tímidas voces que proponían salidas menos punitivas fueron acalladas por los ecos de un coro mundial prohibicionista, bajo la batuta de los Estados Unidos.

El tráfico ilegal de drogas tiene dos caras, una la de Estados Unidos en su condición de país consumidor, y dos, la de Colombia en sus diversos papeles de productor, procesador y comercializador $^{8}$. Para entender la incorporación del control de drogas en la agenda binacional, primero es necesario analizar la manera como se fueron desarrollando estos roles en cada uno de los países.

\subsection{EL CRECIMIENTO DEL CONSUMO EN ESTADOS UNIDOS}

La Guerra de Vietnam no solo trajo consigo la mayor derrota militar de toda la historia de los Estados Unidos, sino también el aumento del consumo de marihuana y heroína de manos de los soldados provenientes del Oriente. Para 1968 el 60\% de los soldados estadounidenses en Vietnam consumía marihuana y en 1973 se estimaba que el 34\% había usado heroína frecuentemente, lo cual generó preocupación entre los sectores conservadores de la población, que temían la acción de "soldados-drogadictos" en las calles de las principales ciudades de la Unión Americana (Matthiesen, 2000, p. 74).

También el tráfico de heroína proveniente del Sureste asiático hacia las ciudades norteamericanas aumentó, usándose incluso como medios de transporte las bolsas y ataúdes de los cadáveres de los soldados muertos en combate. Aunque el Congreso reclamaba acciones para detener el consumo, los militares no interfirieron con la red de tráfico que se había construido a través de los soldados (vivos o muertos) repatriados'; los soldados incluso argumentaban que esas sustancias les ayudaban a aliviar las tensiones de la guerra. Se tomaron como únicas medidas el desestimulo al consumo de heroína en favor de la marihuana, y estadías de "desintoxicación" de los soldados en Europa antes de regresar a casa. Para algunos autores

8. Si bien se reconoce que Colombia también es un país consumidor, como lo señalan las cifras y conclusiones presentadas en la investigación de Larreamendy-Joerns \& Vence (2011), en la que se señala que "una de cada 100 personas abusa de sustancias y aproximadamente una de cada 200 sufre dependencia, situación que es aún más crítica en el caso de los hombres" y que "a pesar de su obvia importancia, las políticas de reducción de la demanda han sido comparativamente invisibles nacionalmente", el presente artículo se concentrará en el papel de productor y comercializador de Colombia, a través de los traficantes de drogas.

9. Este episodio temprano del tráfico ilegal de narcóticos hacia los Estados Unidos fue recientemente recreado por el director Ridley Scott en la película "American Gangster" del año 2007, en la cual se narra la manera como Frank Lucas, traficante afroamericano de Harlem-Nueva York, introdujo heroína en los ataúdes de soldados repatriados de Vietnam. 
este tránsito por Europa hizo que el consumo se propagara en países como Alemania (Atehortúa Cruz \& Rojas Rivera, 2008) .

El aumento del consumo de estas dos sustancias también se encuentra asociado paradójicamente al rechazo que provocó la guerra de Vietnam en sectores importantes de la juventud norteamericana, que acogiendo los valores contraculturales de la "Generación Beat"10, reencarnados en el movimiento "Hippie", comenzó a consumir marihuana, sobre todo de origen mexicano, y cocaína dentro de un marco cultural que pretendía rechazar la violencia, el capitalismo, las estructuras de poder de la sociedad y olvidarse de los horrores de la guerra. En consecuencia se desarrolló un negocio que se hacía cada vez más rentable, que fue apropiado por la estructura mafiosa surgida del tráfico ilegal de licor, los juegos clandestinos, “y del dominio callejero que, con raíces sicilianas, experiencia en Chicago y contactos con los recientes exiliados cubanos, buscó en México y luego en Colombia el producto necesario para surtir su mercado" (Guillou, Rojas, \& Atehortúa, 2009, p. 74).

Otra razón para el aumento del consumo de drogas en los años sesenta es la explosión demográfica posterior a la Segunda Guerra Mundial, el Ilamado "baby boom", que hizo que esta década estuviera dominada por los jóvenes, más inclinados a explorar nuevas experiencias y emociones. Asimismo los cambios en los patrones de consumo, derivados del espectacular crecimiento económico de los Estados Unidos, contribuyeron a este fenómeno tal como lo propone David Musto" (citado por Matthiesen, 2000, p. 75): "Toda esta productividad y dinero crearon un mercado sin paralelo para los bienes de consumo y para todo lo demás que prometiera hacer que la gente se sintiera bien, incluidas las drogas".

El crecimiento económico significó el deterioro de las ciudades por efecto de la reducción de empleos urbanos como consecuencia del incremento de la vida suburbana de las clases medias, afectando sobre todo a los jóvenes de las minorías y de las poblaciones con bajos ingresos, empujados a la economía informal o ilegal, como la de las drogas. Así, de manera recurrente en esta narrativa, se asociaron afroamericanos, mexicanos y puertorriqueños al tráfico ilegal, al incremento del consumo y en consecuencia al aumento de la criminalidad en las principales ciudades norteamericanas. Con ello se reforzaron las percepciones "peligrosistas" sobre el problema asociadas a las minorías deprimidas.

10. “Durante los años 50 del siglo XX surgió un grupo de autores con una clara postura en contra de los valores mayoritarios de la cultura norteamericana. La Generación Beat se caracterizó por su desafío a la sexualidad establecida, el uso habitual de drogas y una gran influencia de otras culturas, sobre todo orientales" (Lecturalia.com, 2012).

11. David Musto (1936-2010) estadounidense experto en políticas de control de drogas y en la Guerra contra las Drogas. Se desempeñó, entre otros cargos, como asesor presidencial durante la administración de Jimmy Carter. Escribió varios libros sobre el tema, entre ellos: "The American Disease: Origins of Narcotic Control" (1973) y "The Quest for Drug Control: Politics and Federal Policy in a Period of Increasing Substance Abuse, 1963-1981" (2002) junto con Pamela Korsmeyer. 
La respuesta de los gobiernos demócratas de Kennedy y Johnson a la presión nacional para disminuir el consumo, reducir el crimen y el tráfico internacional de drogas, fue la de poner énfasis en las medidas que limitaban el abuso de drogas y la demanda. También se desestimaron los argumentos conservadores que vinculaban uso de drogas y aumento del crimen. Así lo observa Eric Schlosser (2000, pág. 31): “(...) se reexaminaron las leyes sobre marihuana que por décadas habían llevado a prisión a negros y mexicanos pobres, sin mayor protesta pública. La política contra el abuso de las drogas evolucionó de un enfoque puramente penal a otro motivado por los intereses de salud pública, con mayor énfasis en el tratamiento y no en el castigo".

Pero esta línea de política pública cambió radicalmente con la elección del republicano Richard Nixon (1968), quien elevó el problema a un estatus presidencial y de alta prioridad, en razón a su "agenda de ley y orden" y a una creciente opinión pública favorable hacia medidas más punitivas: "Si no podemos destruir la amenaza de las drogas en América, entonces seguramente el tiempo nos destruirá. Yo no estoy preparado para aceptar esta alternativa" (Matthiesen, 2000, p. 78).

Planteado el consumo y el tráfico de drogas como una amenaza a los hogares y a la misma nación por parte del mismo presidente, quien afirmaba que "el abuso de las drogas es el enemigo número uno de Estados Unidos", la respuesta se extendería también al ámbito de la defensa, denominando la acción de control a partir de 1973 como una "una guerra global-total contra la amenaza de las drogas" (Revista Time, 2009). La estrategia se extendió a ambos lados del problema, la oferta y la demanda, y para ello se aprobaron normas y se crearon instituciones que permitieron, a alto nivel, atacar la producción y distribución de drogas, así como fomentar la rehabilitación, la prevención y la investigación sobre el abuso de las sustancias prohibidas. El propósito era disminuir la oferta desde la fuente (el extranjero) y reducir la demanda interna.

Aunque la administración Nixon fue la primera en darle mayor atención a la reducción de la demanda, creando nuevas instituciones, asignando más presupuesto y proponiendo tratamientos como la metadona para los adictos a la heroína, el foco de la estrategia fue el control del tráfico y la distribución, con el fin de reducir la droga disponible en las calles. Para ello se apuntó a la interceptación de envíos en las fronteras nacionales y a su destrucción en los países de origen. La creación de la DEA (Drug Enforcement Administration) en 1973 permitió que una sola agencia federal dirigiera las acciones de la guerra contra las drogas, traduciéndose este nuevo diseño institucional en un aumento significativo de la población carcelaria relacionada con el consumo y tráfico de sustancias psicoactivas.

El objetivo de la estrategia de Nixon, centrada más en acuerdos bilaterales que en la plataforma multilateral constituida con la Convención Única sobre Estupefacientes de 1961 y demás regulaciones de Naciones Unidas, era erradicar el problema de la droga en la fuente ${ }^{12}$. Es decir, reducir los cultivos de amapola y marihuana para interferir en la disponibilidad de drogas en las calles de los Estados Unidos, que por ese entonces proveía sobre todo Turquía vía Francia (opio), 
y México (marihuana). El gobierno de los Estados Unidos firmó acuerdos bilaterales de cooperación con Francia, Turquía y México para la reducción de los cultivos, y del procesamiento. En consecuencia Francia ayudó a desarticular la "French Connection"13 y Turquía se comprometió a no producir más opio a cambio de compensaciones financieras de EE.UU. para aliviar la suerte de los campesinos turcos dedicados a esta actividad.

En Jamaica y México se buscó eliminar la marihuana, mediante la erradicación de los cultivos y la persecución a los traficantes, a través de las operaciones "Bucanero" en el primer país (Tokatlian J. G., 1998) y la "Cóndor", en el segundo. Entre 1975 y 1980 se desarrolló en México la estrategia, que pareció exitosa en un principio, en tanto que se redujo el área cultivada, se disminuyeron las exportaciones a Estados Unidos y se interrumpieron temporalmente los canales de acceso a dicho mercado, pero no lo fue tanto en el largo plazo. Como afirma Velasco (2010, pág. 12):

"México estaba preocupado de que el fracaso de sus políticas antidrogas pudiese poner en jaque la autonomía de futuras políticas ante Estados Unidos. Se montó entonces la operación de erradicación de cultivos de droga más ambicioso en la historia del país. Miles de hectáreas de cultivos de marihuana y amapola fueron quemadas. Esto redujo la participación de México en el mercado Estadounidense del 70 al 10 por ciento para 1983, sucedió algo muy similar con la heroína. (Craig, 1989, p. 251). Se gastaron más de 35 millones de dólares en la campaña de erradicación de 1975-1976. El gobierno estadounidense gastó un millón de dólares por cada 4 gastados por el gobierno mexicano. Se implementaron cerca de 5000 soldados y 350 miembros de la PJF (Toro, 1995, p. 18). Desgraciadamente la campaña fue exitosa sólo por algunos meses, ya que los cultivos de opiáceos lograron encontrar lugar seguro en otras partes de las múltiples sierras mexicanas. El único logro real de la Operación Cóndor fue forzar a las redes del narco a buscar otras tierras para sus cultivos en lugares más seguros o más inaccesibles".

Hoy, según cifras de la Interpol de 2012, la totalidad de la heroína producida en México va destinada a los mercados del occidente de los Estados Unidos y el lado oriental es abastecido por la que procede de Colombia: "Para transportar la heroína a Estados Unidos, los traficantes colombianos utilizan itinerarios que discurren a través de Venezuela, Argentina, Ecuador, Panamá y México". En cuanto a la marihuana, Jamaica, México y Colombia siguen estando en la lista de países exportadores, ahora junto con los Estados Unidos, que la produce para su propio consumo (INTERPOL, 2012).

12. El gobierno de Estados Unidos estimaba en 1970 que unos 26 millones de ciudadanos consumían o habían consumido marihuana y unos 8 millones LSD (Escohotado, 1996, p. 154).

13. La Conexión francesa (en inglés "French Connection") se conoció como la red de narcotráfico destinada a introducir heroína a los Estados Unidos, desde Turquía, pasando por Francia. Durante los años sesenta y setenta, época de su auge, fue responsable de la mayor parte de la heroína consumida en Estados Unidos. 


\subsection{EL AUMENTO DE LA PRODUCCIÓN DE MARIHUANA Y COCAÍNA EN COLOMBIA}

Por cuenta de la Operación Cóndor llegamos a Colombia, ya que el interés de los consumidores de marihuana mexicana se desplazó por razón del miedo a los efectos del Paraquat (sustancia usada para la erradicación) a variedades producidas dentro de los mismos Estados Unidos y a las importaciones del cáñamo colombiano, considerado más suave. Una hipótesis sostenida por varios autores es que la marihuana colombiana fue conocida en Estados Unidos, al inicio de los años sesenta, gracias a los ciudadanos estadounidenses presentes en el país como parte del programa Cuerpos de Paz de la Alianza para el Progreso, quienes contribuyeron a su difusión y primeras etapas de comercialización al regresar a su nación.

El cultivo de marihuana a gran escala sería organizado por traficantes de Antioquia y la Costa Atlántica que se comportaron como proveedores desde Colombia, sin participar de las redes de distribución en los Estados Unidos. Para 1978 Colombia era el principal productor y exportador de cannabis a los Estados Unidos, aportando entre el 60\% y 65\% de las cien mil toneladas de marihuana introducidas a ese país, cultivadas en un área de 25.000 a 30.000 hectáreas de la geografía nacional (Tokatlian, 1998, p. 49).

Como lo veremos más adelante, Washington también le impondría una estrategia de erradicación a Bogotá adaptada de la mexicana. Algunos autores sugieren que el comercio ilegal de marihuana tuvo éxito en Colombia debido a una tradición local de contrabando y a que muchas de las rutas y estructuras utilizadas para el envío de las mercancías que evitaban las aduanas fueron luego usadas para exportar la "bonanza marimbera", especialmente en la Guajira y Urabá, zonas habituales de ese delito fiscal. Los marimberos, es decir, las personas encargadas de transportar, vender y entregar la marihuana en Estados Unidos, provenían sobre todo de la Costa Atlántica de Colombia, desde donde "la mercancía" se despachaba por barco y aviones particulares, en una época de menores controles fronterizos (Castillo, 1987).

La mayor rentabilidad del negocio permitió su tecnificación (uso de aviones y barcos mejor equipados) y la ampliación de su escala, al sustituir a los proveedores mexicanos y jamaicanos que se habían visto afectados con los controles impuestos a estos dos países proveedores. El negocio de la marihuana no duraría mucho ante el crecimiento del abastecimiento local dentro de EE.UU. y las preferencias de los consumidores por una sustancia distinta que empezaba a ser más atractiva para la generación de estadounidenses de finales de los años setenta, sobre todo para los ejecutivos yuppies ${ }^{14}$, que preferían un estimulante más acorde con la época:

14. Acrónimo proveniente del inglés que designa "Young urban professional" o "Joven Profesional Urbano" en español. Término de uso común hasta los años noventa en Estados Unidos para referirse a un miembro de la clase media alta entre 20 y 40 años de edad. 
La bonanza de la marihuana duró poco. La confiscación de la hierba a cargo de la Guardia Costera y el Servicio de Aduanas de Estados Unidos empezó a declinar en 1981. El precio de la marihuana en el mercado colombiano también empezó a descender, por lo que no es aventurado suponer que la bonanza llegó a su fin en ese año (López, 2000, p. 102).

La cocaína ya era conocida en los Estados Unidos, siendo legal su consumo sin prescripción médica antes de la Ley Harrison; incluso es bien sabido que hasta 1914 era uno de los componentes de la Coca-Cola. En los años setenta su consumo fue asociado al bienestar y el éxito social, encarnado en artistas de vanguardia, ejecutivos y políticos que transmitían una "selecta atmosfera de placer y mundanidad" y que a la vez permitía "imitar a marginales sin marginarse", con una sustancia que no amenazaba llevar de "viaje" a nadie (Escohotado, 1996, p. 171). Para 1970 unos cinco millones de estadounidenses se consideraban consumidores habituales de cocaína, adquiriéndola a bajos precios y con menor riesgo de intoxicación, a diferencia de la heroína, los barbitúricos, las anfetaminas e incluso el alcohol. El consumo de la cocaína iría en aumento; en 1972 se calculaba en 30 millones de personas y para 1974 el 42\% de los adultos habrían usado alguna vez esta sustancia (Escohotado, 1996).

Entonces aparecieron los narcotraficantes colombianos, que si bien ya desde los años sesenta comienzan a surtir la creciente demanda estadounidense por cocaína ${ }^{15}$, es solo hasta los años ochenta que se consolidan como sus principales proveedores; los primeros narcotraficantes colombianos de cocaína desarrollaron un comercio artesanal y al menudeo, a través de pequeños envíos en vuelos comerciales. Serán las ganancias y la creciente rentabilidad del negocio lo que propiciará su tecnificación, expansión y control, desplazando violentamente a los intermediarios, sobre todo cubanos, en las propias calles de las ciudades estadounidenses.

A finales de los años setenta Miami y Nueva York serán testigos de la violencia y corrupción que pueden desatar los narcos colombianos, con sus sicarios y la sevicia de sus crímenes. Aterradoras escenas que serán recreadas en la película Scarface del año 1983, de Brian de Palma y Oliver Stone. Los narcos colombianos se impondrán sobre todos los "empresarios" del negocio, destacándose por su crueldad, y además por liderar un mundo de hombres, la "Reina de la Coca", Griselda Blanco, a quien se le atribuye haber asesinado a más de doscientos cincuenta personas, incluyendo dos de sus maridos. También se le conocerá como "La Madrina" y la iniciadora de Pablo Escobar en el negocio de las drogas.

En 1980 la DEA constataba la creciente capacidad de los narcos colombianos en el negocio, al reconocer que durante ese año habían ingresado ilegalmente a su territorio cincuenta

15. "Para 1965 los colombianos proporcionan casi el 100\% de la cocaína que se movía a través de las redes cubanas. Los colombianos refinaban la droga, y los cubanos la transportaban y distribuían a los Estados Unidos" (López, 2000, p. 101). 
toneladas. Colombia se había convertido en la fuente de casi toda la cocaína que llegaba a ese mercado, primero como procesador, a partir de pasta base de coca que se adquiría en los mercados de Perú y Bolivia, y luego como productor con sus propios cultivos (Guillou, Rojas, \& Atehortúa, 2009).

El poder alcanzado por los narcotraficantes colombianos cristalizó en los Carteles de Medellín y Cali, el primero liderado por Pablo Escobar (1951-1993) y en el que participaban, entre otros, Gonzalo Rodríguez Gacha (1947-1989), Carlos Lehder y el clan de los Ochoa (una tradicional familia antioqueña), y el segundo bajo el mando de los hermanos Miguel y Gilberto Rodríguez Orejuela. Si bien los métodos usados por estas dos agrupaciones diferían (la primera se basaba más en la intimidación y la violencia, y la segunda en la construcción de una red compleja de vínculos sociales, políticos y culturales), ambas llegarían a desestabilizar la institucionalidad colombiana en los años ochenta.

Ante el aumento creciente del consumo en Estados Unidos y la mayor capacidad de exportación de los narcotraficantes colombianos, así como su creciente poder de desestabilización del Estado colombiano frente a una sociedad que los había visto avanzar sin mostrar la suficiente voluntad para detenerlos, las únicas medidas de control que se desarrollaron fueron las propuestas por Estados Unidos, derivando en una creciente "internalización" del diagnóstico norteamericano por parte del gobierno de Colombia: erradicación de cultivos ilícitos con herbicidas, y persecución a los narcotraficantes, como en el caso mexicano.

\section{LA “INTERNALIZACIÓN” EN COLOMBIA DE LA GUERRA CONTRA LAS DROGAS}

El crecimiento del problema de las drogas a distintos niveles era evidente, expresándose a nivel interno en el vínculo progresivo de los narcotraficantes con la política regional, el aumento de la violencia en las grandes ciudades y la guerra contra la institucionalidad declarada por los narcotraficantes luego de la puesta en ejecución, a comienzos de los años ochenta, del tratado de extradición con los Estados Unidos suscrito en 1979. Frente a los vínculos con la política regional, los casos más evidentes son los de Pablo Escobar, que funda el movimiento "Medellín sin Tugurios", a través del cual construye viviendas, escuelas deportivas y canchas de futbol en barrios marginados. En 1982 es elegido representante a la Cámara como suplente del político liberal disidente Jairo Ortega e incluso participa en la comisión oficial que asiste a la toma de posesión del presidente español Felipe González.

Por su parte Carlos Lehder funda en 1981 el "Movimiento Civil Latino Nacional", cuya reivindicación principal era luchar contra la extradición; también publica el semanario "Quindío Libre", distribuyendo cincuenta mil ejemplares. Más tarde Rodríguez Gacha también establece vínculos con la política a través de la financiación al ultraderechista "Movimiento de Restauración Nacional -MORENA", fundado en 1989 por líderes liberales y paramilitares del Madalena Medio. 
Los hermanos Rodríguez Orejuela, del Cartel de Cali, asumieron un perfil más bajo en la política que el de Escobar y Lehder, sin intervención directa y optando más por la financiación de campañas electorales de autoridades locales y congresistas; además establecieron fuertes vínculos económicos y sociales con las élites regionales. Se llegó a decir que los Rodríguez tenían el poder suficiente para "citar a una convención liberal" o "reunir quórum en el Congreso" (Guillou, Rojas, \& Atehortúa, 2009, p. 85).

La violencia de los narcotraficantes se incrementó con la puesta en ejecución (1984) del tratado de extradición entre Colombia y Estados Unidos, que permitía el traslado de nacionales acusados de delitos en cualquiera de los dos territorios. La respuesta de los narcos, además del desarrollo de estrategias jurídicas y políticas de negociación con el Estado, fue el terrorismo, el secuestro, el asesinato selectivo y en general el amedrentamiento de la sociedad colombiana.

Los carteles construyeron ejércitos privados. Pablo Escobar recurrió a jóvenes pobres de las comunas de Medellín, mientras Rodríguez Gacha reclutó campesinos de las regiones de su influencia, y los Rodríguez Orejuela a militares retirados y activos de los cuerpos de seguridad del Estado. Contrataron mercenarios extranjeros para su entrenamiento, como el israelí Yair Klein, se asociaron con paramilitares del Magdalena Medio, y se aliaron con sectores del Departamento Administrativo de Seguridad (DAS) y de la policía.

Escobar y sus socios fundarían el MAS (Muerte a Secuestradores) a raíz del secuestro en 1981, por parte de la guerrilla M-19 (Movimiento 19 de Abril), de Martha Nieves Ochoa Vásquez del clan Ochoa. La confluencia de intereses anti-insurgentes entre esta organización y sectores de la fuerza pública abriría el camino para futuras "colaboraciones".

Las acciones de los narcotraficantes, sobre todo del Cartel de Medellín, que más impacto tendrían en la sociedad colombiana serían el asesinato y el terrorismo, dirigidas a acallar a los sectores políticos y sociales que comenzaban a denunciar la procedencia de sus fortunas e impedían su ingreso a la vida política nacional. Así, en abril de 1984 asesinan al ministro de Justicia Rodrigo Lara Bonilla, y dan inicio a una guerra declarada contra el Estado y la sociedad que se extendería hasta la misma muerte de Escobar en 1993. Para 1986 fundan el grupo "Los Extraditables", como una organización armada clandestina que buscaba la derogación del tratado de extradición, acuñando el lema "Preferimos una tumba en Colombia a una cárcel en Estados Unidos".

Además del ministro de Justicia, los narcotraficantes asesinaron policías, jueces, magistrados y periodistas. Asesinaron también a Guillermo Cano (1986), director del diario El Espectador; a Jaime Pardo Leal, líder de la coalición de izquierdas Unión Patriótica (1987); se atentó en Hungría contra el ex ministro de Justicia, Enrique Parejo (1987); se secuestró al periodista y político Andrés Pastrana (1988) y en un intento de secuestro se asesinó a Carlos Mauro Hoyos, Procurador General de la Nación (1988). También les quitaron la vida al gobernador en ejercicio de 
Antioquia, Antonio Roldan Betancourt (1989) y al comandante de la policía de ese departamento, Valdemar Franklin Quintero (1989). El 18 de agosto de 1989 asesinan a quien figuraba como seguro ganador de las elecciones presidenciales de 1990, Luis Carlos Galán.

\subsection{LAS RESPUESTAS INSTITUCIONALES AL PROBLEMA DE LAS DROGAS Y AL CRECIEN- TE PODER DE LOS NARCOTRAFICANTES}

Juan Gabriel Tokatlian señala que el tipo de proceso de toma de decisión de la política exterior de Colombia, en donde el papel de la Cancillería se limita más a un "Ministerio de Fronteras" que a una agencia pública en donde se diseñan y ejecutan estrategias de estado de largo plaza para el tratamiento de los diversos temas internacionales, así como el tratamiento cerrado frente a temas político-estratégicos, como el narcotráfico, limitan las posibilidades de participación más amplia de fuerzas sociales y políticas que permitan la construcción de respuestas consensuadas y estructurales a las problemáticas que se enfrentan. En contraste con lo que sucede en países como México o Brasil, en donde las cancillerías son mucho más fuertes, la multiplicidad de "diplomacias", según los temas, hacen pensar que en el caso de Colombia se está ante un Estado relativamente débil y fragmentado y no frente a uno centralizado y dotado de poder (Tokatlian, 1991, p. 286).

El narcotráfico, definido como un asunto de seguridad nacional, en el centro de la agenda político diplomática, hace que las decisiones se tomen más en el ámbito de una especie de "red de enlace", en torno a la Presidencia y en la que participan diversas actores como agencias públicas, gremios, militares, y funcionarios estadounidenses. La débil participación del Congreso de la República en el proceso de toma de decisiones de la política exterior hace que el debate político interno se restrinja, incrementándose la influencia de actores ajenos a la institucionalidad nacional, como los agentes del gobierno estadounidense. La respuesta que se ha dado a los problemas asociados al narcotráfico, como la militarización mediante la guerra contra las drogas, la extradición de nacionales a Estados Unidos, la erradicación de cultivos ilícitos con herbicidas, la negociación Estado-narcotraficantes, muestra la falta de una respuesta nacional coherente y pertinente con un diagnóstico local, construido de manera participativa y democrática, y "corrobora la paulatina "internalización" del diagnóstico estadounidense por parte de Colombia acerca de cómo confrontar el narcotráfico" (Tokatlian, 1991).

En 1978 el narcotráfico ya era un asunto sensible de las relaciones entre Colombia y EE.UU. El incremento de cultivos y de las exportaciones de marihuana colombiana hacia la Unión Americana, así como el éxito de las erradicaciones con herbicidas en México y Jamaica hicieron que el gobierno de Jimmy Carter presionara al de Julio Cesar Turbay Ayala para que las implementara en Colombia, especialmente en la Guajira. La respuesta del gobierno nacional estuvo por fuera de lo esperado por Washington, dado que no se asumió de manera inmediata, en razón a la presión interna de sectores sociales y políticos que temían las consecuencias de los herbicidas en los ecosistemas y la economía campesina local. A pesar de lo anterior, en 1984 se asume el 
uso de herbicidas químicos para el control de dichos cultivos, sin importar las razones ambientales y económicas de los actores nacionales.

En consonancia con la declaración de guerra contra las drogas desde los Estados Unidos, el gobierno de Turbay Ayala expidió el Decreto 2144 de 1978 orientado a involucrar al Ejército Nacional en las labores de control del tráfico ilegal y de persecución de narcotraficantes, bajo la retórica de la "turbación del orden público" y de la prevención de "prácticas terroristas dirigidas a producir efectos políticos que desvertebran el régimen republicano vigente" que orientaba a este gobierno (Tokatlian, 1998).

El presidente Turbay, acusado en 1978 en el programa de televisión de Estados Unidos 60 Minutes de tener vínculos con las mafias de la marihuana, quería dar muestras de su compromiso con la lucha contra las drogas, optando por una solución militar y de fuerza alineada con la postura de Washington. A esta condición se sumaba las declaraciones del director de la DEA, Peter Bensinger, que reclamaba más mano dura contra los narcotraficantes y pedía que Colombia considerara este problema como de "seguridad nacional". Afirmaciones que fueron calificadas de intromisión en los asuntos internos de Colombia por parte de los funcionarios nacionales, pero que en el largo plazo serían incorporadas en la política interna e internacional del país.

Sumado a la presión de Washington el presidente Turbay se encaminó por la vía militar para el combate de los narcotraficantes por razones también de orden interno: auge de este nuevo sector social económicamente poderoso; aumento de la criminalidad asociada al comercio ilegal de la marihuana, especialmente en la costa norte del país; incremento de la corrupción en funcionarios públicos y agentes de seguridad del Estado; y especialmente "entorpecimiento de la temática de los narcóticos en su búsqueda de una relación más estrecha con Washington" (Tokatlian, 1998). En el fondo, la idea que orientaba al gobierno Turbay era que mediante el uso de medidas de fuerza, al igual que en el caso del manejo de las guerrillas, las soluciones serían rápidas y eficaces. Idea que además se impuso ante la falta de voces disidentes a la propuesta norteamericana frente al manejo del problema del cultivo, producción y comercialización de drogas desde Colombia hacia los Estados Unidos.

De esta forma, en noviembre de 1978 se implementa la "Operación Fulminante", destinada a combatir militarmente en la Guajira y la región atlántica la producción y el tráfico de marihuana, mediante la asignación de 10.000 soldados de la Segunda Brigada. Esta iniciativa del Ejecutivo contó con el apoyo e influencia de las autoridades estadounidenses que confiaban en que la participación de militares derivaría en resultados eficaces.

Los resultados de la operación en el corto plazo (1979) fueron ambiguos. Por una parte se decomisaron 3.500 toneladas de marihuana, se incautaron 97 aviones y 78 embarcaciones, se destruyeron más de 10.000 hectáreas de plantaciones y se detuvieron a centenares de "marimberos". De otro lado, aumentó la incidencia de casos de corrupción militar y civil, se 
agudizaron los problemas sociales en la costa norte derivados de la pérdida de ingresos de campesinos y comerciantes asociados al negocio, y se incrementaron las críticas ya frecuentes al estamento militar por los excesos cometidos, además de expresarse dudas sobre la coherencia de las políticas antidroga.

A pesar del apoyo estadounidense y el llamado del Departamento de Estado de los EE.UU. a ampliar la estrategia a nivel nacional, la opción militar parecía declinar por razones de política interna. En primer lugar, los militares se sentían haciendo labores de policía en detrimento de la guerra contra las guerrillas de las FARC, el M-19, el EPL y el ELN, las cuales luego de una época de estancamiento se incrementaban en número y capacidad, y a las que los militares reconocían como un objetivo más acorde con su misión constitucional. La pérdida de imagen y credibilidad del Ejército frente a la población civil, en una guerra irregular que no reconocían como suya, hizo que la "Operación Fulminante" se terminara en marzo de 1980. El presidente haría un cambio en la estrategia, trasladando el tema a la policía y convocando a la sociedad a unir esfuerzos para derrotar a los narcotraficantes. Sólo dos décadas después, en momentos del Plan Colombia (años dos mil), los militares volverían a involucrarse en la guerra contra las drogas.

A la par que se desarrollaba la "Operación Fulminante" arreciaban las presiones de Washington sobre Bogotá, para recurrir a la erradicación de cultivos con Paraquat, el agente químico usado para la erradicación en México y Jamaica. De esta forma en 1979 el Subcomité de Relaciones Hemisféricas del Congreso de Estados Unidos aumentó los recursos de ayuda a Colombia para combatir el narcotráfico, y tres senadores del Select Committee on Narcotics Abuse and Control visitaron a Turbay para persuadirlo sobre el uso del herbicida. El presidente se mantuvo en la posición técnica de no usarlo debido al debate interno e internacional sobre las consecuencias ecológicas de su uso, frente a la posición, argumentada desde la política, de Washington. No obstante esta posición no implicó un rompimiento con Washington dado que el Ejecutivo colombiano demostraba suficientemente su compromiso al militarizar la lucha contra las drogas.

En síntesis, el presidente Julio Cesar Turbay Ayala quiso con su política antidrogas despejar las dudas en torno a la corrupción "marimbera" que ensombrecieron su campaña y el inicio de su mandato, adelantando una ofensiva diplomática y jurídica para acentuar la importancia del tema de las drogas en su política interna e internacional, y la necesidad de contar con el respaldo de Estados Unidos para este propósito. Aunque públicamente las relaciones entre los dos países parecían de bajo perfil, a nivel diplomático lo fueron de alto nivel.

En este período, Colombia también firmó acuerdos de cooperación frente al control del tráfico ilegal de narcóticos con Ecuador, Perú, Honduras, República Dominicana y Brasil; y a nivel interno se ratificó en 1979 el "Acuerdo Sudamericano sobre Estupefacientes y Psicotrópicos", y en 1980 el "Convenio sobre sustancias sicotrópicas". Pero tal vez el instrumento internacional más importante, y que también más consecuencias y debates suscitaría, fue el tratado de 
extradición firmado en 1979 por Turbay y Carter, bajo un aura de "quiet diplomacy" en Estados Unidos y de "diplomacia reservada" en Bogotá. (Tokatlian, 1991).

El tratado se firmó por la presión de Washington pero también por el convencimiento colombiano de su aporte a la solución del problema del narcotráfico y por la postura de convergencia con Estados Unidos de la administración Turbay. Esta fue la oportunidad del gobierno estadounidense para imponer su agenda frente a la lucha contra las drogas y así limitar la autonomía colombiana para resolver el problema por otras vías. La ausencia de debate público en Colombia y Estados Unidos hizo que se impusieran las razones de Washington frente a voces no gubernamentales distintas.

El instrumento sería ratificado en 1980 por el Congreso de Colombia a pesar del intenso debate y las críticas al gobierno de Turbay y la desconfianza del gobierno estadounidense hacia el Congreso, al que consideraba infiltrado por dineros del narcotráfico en un $10 \%$ de su composición. Finalmente, mediante la Ley 27 de noviembre 3 de 1980, se sanciona el tratado de extradición. El efecto no esperado más perverso de este instrumento fue la organización de las mafias en torno a su rechazo, aumentando con ello su potencial desestabilizador del Estado y la sociedad colombiana:

Así se sellaba un capítulo adicional de la lenta pero firme "internalización" del diagnóstico oficial norteamericano en cuanto a la estrategia para llevar a cabo el combate contra las drogas. En síntesis, hacia la segunda mitad de la administración del presidente Julio César Turbay Ayala, los lazos colombo-norteamericanos en materia de lucha contra los narcóticos se habían estrechado. La óptica represiva cobraba un sello distintivo. A pesar de la retórica sobre la naturaleza multilateral y multifacética del fenómeno de los narcóticos, se optó por una política de corte bilateral determinada por las relaciones Bogotá-Washington y apoyada en mecanismos de fuerza. (Tokatlian, 1991, p. 314).

\section{CONCLUSIÓN}

La lucha contra el tráfico ilegal de drogas se vuelve un asunto relevante en las relaciones de Colombia y Estados Unidos en razón a varias circunstancias. Primero, al incremento creciente del consumo en los Estados Unidos durante las décadas del sesenta, setenta y ochenta, que provocaron el aumento de la producción de drogas (marihuana y cocaína) en Colombia y en consecuencia el incremento del poder de los narcotraficantes.

Segundo, a la respuesta de control del gobierno de los Estados Unidos hacia los países productores, buscando la erradicación de cultivos, la interdicción de drogas y la persecución a los narcotraficantes, para la cual era fundamental la participación del gobierno colombiano y el alineamiento de este con la estrategia propuesta por Washington. La falta de una estrategia 
local, construida democráticamente con sectores políticos, sociales y académicos, además de los éxitos parciales en México y Jamaica, facilitó la aceptación del diagnóstico y la solución propuesta por el gobierno estadounidense.

Tercero, el poder creciente de los narcotraficantes y su búsqueda de poder político y social, así como su lucha contra el tratado de extradición, intimidaron a la sociedad colombiana y a los sectores políticos que avizoraban su capacidad desestabilizadora, haciéndose necesaria una alianza más estrecha con Washington. Por último, la confluencia de percepciones de Washington y Bogotá sobre la prohibición, la interdicción y la persecución permitieron que el diagnóstico y las soluciones de Estados Unidos frente al problema se instalaran definitivamente en las relaciones bilaterales.

A cuarenta años de la puesta en marcha de la guerra contra la drogas, y ante su fracaso, dado el mantenimiento del negocio y las devastadoras consecuencias en términos de violencia y corrupción en los países productores y comercializadores, las voces que reclaman una política diferente para el tratamiento del tráfico ilegal de narcóticos, hoy tienen mayor eco que en el pasado. Así lo mostró la pasada Cumbre de las Américas de Cartagena (14 y 15 de abril de 2012) que llevó al escenario presidencial interamericano la necesidad de pensar en otras estrategias que contemplen incluso la legalización de la producción.

Hoy todavía el $80 \%$ de la cocaína del mundo se produce en Colombia. Este país sigue siendo un exportador importante de marihuana y heroína, sobre todo hacia los Estados Unidos; el tráfico de estas sustancias involucra a países de Centroamérica, Suramérica, Caribe oriental, Europa e incluso África occidental, aportando no solo al incremento de la criminalidad y la corrupción, sino también al consumo en esas zonas (INTERPOL, 2012).

A pesar de que Colombia logró la desestructuración de los poderosos carteles de la droga, eliminó a Pablo Escobar, el "narco" por antonomasia, a su socio Rodrigo González Gacha, se apresaron a los miembros del clan Ochoa y de los Rodríguez Orejuela; se han extraditado más de 1221 nacionales (entre 2000 y 2010), sobre todo a los Estados Unidos, incluyendo a Carlos Lehder y recientemente a los jefes del paramilitarismo; y se han perseguido y encarcelado a sus testaferros; nuevos "micro-empresarios" de las drogas han surgido para reemplazar a los extraditados, prófugos o asesinados y no sólo en Colombia sino también en otras latitudes. Mientras el negocio siga siendo tan lucrativo, los estados, sean propicios, o débiles, frente al poder corruptor de las mafias, y el consumo se mantenga o incluso aumente, el narcotráfico seguirá siendo una opción atractiva para muchos.

La salida al problema parece ya no estar en un escenario de guerra frontal y de criminalización de la producción, el tráfico y el consumo. Veremos si la legalización se abre camino y si los países que han puesto una cuota alta de sacrifico en esta guerra contra las drogas, como Colombia, son capaces de impulsar a nivel bilateral y multilateral otras alternativas distintas a las punitivas. 


\section{BIBLIOGRAFÍA}

- $\quad$ Atehortúa Cruz, A. L., \& Rojas Rivera, D. M. (2008). El narcotráfico en Colombia. Pioneros y capos. Historia y Espacio, 5-20.

- Bussey, J. (2009). Estado frágil, relaciones desgastadas. México, los Estados Unidos y la guerra contra el narcotráfico. Revista Latin Trade, 22-26.

- Castillo, F. (1987). Los Jinetes de la Cocaína. Bogotá: Documentos Periodísticos.

- $\quad$ Congreso de Colombia. (15 de septiembre de 1920). mamacoca.org. Recuperado el 13 de mayo de 2012, de Ley 11 de 1920: http://www.mamacoca.org/docs_de_base/ Legislacion_tematica/Ley_11_de_1920.htm

- Coordinación Colombia-Europa-Estados Unidos, Observatorio de Derechos Humanos y Derecho Internacional Humanitario. (2005). Cuando la excepción es la regla. Colombia: Estados de Excepción y Regímen Político. Bogotá: Publicaciones Ilsa.

- El Tiempo.com. (13 de marzo de 2012). Santos propone método para debatir legalización de drogas en Cumbre. Recuperado el 15 de noviembre de 2012, de eltiempo.com: http:/ /www.eltiempo.com/politica/ARTICULO-WEB-NEW_NOTA_INTERIOR-11344841.html

- $\quad$ Escohotado, A. (1996). Historia elemental de las drogas. Barcelona: Anagrama.

- Guillou, R., Rojas, D., \& Atehortúa, A. (2009). Reflexión para la planeación. Seguridad Democrática y Política Antidrogas. Bogotá: Ediciones Aurora.

- INTERPOL. (2012). interpol.int. Recuperado el 15 de noviembre de 2012, de http:// www.interpol.int/es/Criminalidad/Drogas/Cannabis

- $\quad$ Larreamendy-Joerns, J., \& Vence, M. F. (2011). La demanda como drama: La prevención y el tratamiento de drogas en Colombia. En A. Gaviria, \& D. Mejía, Política antidrogas en Colombia: éxitos, fracasos y extravíos (pp. 121-145). Bogotá: Universidad de los Andes.

- Lecturalia.com. (2012). Generación beat. Recuperado el 13 de mayo de 2012, de http:// www.lecturalia.com/sobre/generacion-beat

- López, A. (2000). Colombia: de la prohibición a la guerra contra las drogas. El Malpensante, 25, 83-103.

- Matthiesen, T. (2000). El arte político de conciliar. El tema de las drogas en las relaciones entre Colombia y Estados Unidos, 1986-1994. Bogotá: FESCOL, CEREC, FEDESARROLLO. 
- $\quad$ Micklethwait, J., \& Wooldridge, A. (2006). Una nación conservadora. El poder de la derecha en Estados Unidos. Barcelona: Debate.

- $\quad$ Naciones Unidas. Oficina contra la Droga y el Delito. (26 de junio de 2008). Cronología: 100 años de fiscalización de drogas. Recuperado el 15 de Septiembre de 2012, de http:/ /www.unodc.org/documents/26june/26june08/timeline_S.pdf

- $\quad$ ONUDD. (7 de Junio de 2010). Informe de la UNODC: "la delincuencia organizada se ha globalizado convirtiéndose en una amenaza para la seguridad". Recuperado el 2012, de http://www.unodc.org/southerncone/es/frontpage/2010/06/17-crime-organizado-seglobalizou-e-se-transformou-em-uma-ameaca-a-seguranca.html

- $\quad$ Organización de las Naciones Unidas. (1961). Convención Unica de 1961 sobre estupefacientes. Recuperado el 13 de mayo de 2012, de Junta Internacional de Fiscalización de Estupefacientes: http://www.incb.org/pdf/s/conv/convention_1961_es.pdf

- Paige, R. (2000). La guerra contra las drogas: otra impostura. Revista El Malpensante, 25, 14-23.

- $\quad$ Revista Time. (25 de marzo de 2009). The War on Drugs. Recuperado el 14 de mayo de 2012, de http://www.time.com/time/world/article/0,8599,1887488,00.html

- Schlosser, E. (2000). La locura de la hierba. El Malpensante, 25, Septiembre 16-Octubre 31, 25-51.

- $\quad$ Tickner, A., \& Cepeda, C. (2011). Las drogas ilicitas en la relación Colombia-Estados Unidos. En A. Gaviria, \& D. Mejía, Política antidrogas en Colombia: éxitos, fracasos y éxtravios (pp. 205-234). Bogotá: Universidad de Los Andes.

- $\quad$ Tokatlian, J. G. (1991). La política exterior de Colombia hacia Estados Unidos, 1978-1990. El asunto de las drogas y su lugar entre Bogotá y Washington. En C. G. Arrieta, L. J. Orjuela, E. P. Sarmiento, \& J. G. Tokatlian, Narcotráfico en Colombia. Dimensiones políticas, económicas, jurídicas e internacionales (pp. 277-369). Bogotá: Tercer Mundo Editores- Univesidad de Los Andes.

- Tokatlian, J. G. (1998). Política antidrogas de Estados Unidos y cultivos ilícitos en Colombia. La funesta rutinización de una estrategia desacertada. Revista Análisis Político, 47-68.

- Velasco, O. C. (2010). La evolución del Narcotráfico en México. Recuperado el 1 de Septiembre de 2012, de Universidad de Texas: http://lanic.utexas.edu/project/etext/lilas/ilassa/ 2010/velasco.pdf 